\title{
Thorax
}

Editorials

\section{Oedema and cor pulmonale revisited}

\author{
S V Baudouin
}

Over 30 years ago Campbell and Short ${ }^{1}$ stated that cardiac failure was unusual during exacerbations of chronic obstructive pulmonary disease (COPD) and that the description of the associated oedematous state as "cor pulmonale" was likely to be a misnomer. Three of his observations on the origins of cor pulmonale, which emphasise the importance of both chronic hypoxia and hypercapnia, remain equally relevant today - namely, that oedema is rarely present if the arterial carbon dioxide tension $\left(\mathrm{PaCO}_{2}\right)$ is normal; if oedema is present $\mathrm{PaCO}_{2}$ is almost always raised; and the $\mathrm{PaCO}_{2}$ may be raised without oedema being present.

Oedema formation is not limited to patients with COPD but is also found in other types of chronic respiratory failure including neuromuscular disease, thoracic cage deformities, and cystic fibrosis. It rarely, if ever, occurs in interstitial fibrosis. The outlook for the patient is poor following the onset of oedema with five year survival being less than $50 \%{ }^{2}$

The "epidemics" of cor pulmonale seen in the United Kingdom during the late 1950 s and 1960s led to the development of a number of research programmes into the cause of the condition. These focused on three possible mechanisms: (1) cardiac dysfunction due to pulmonary hypertension; (2) abnormalities in the hormonal control of salt and water balance; and (3) changes in renal blood flow and sodium handling.

In their article Campbell and Short ${ }^{1}$ suggested that, to solve the problem of cor pulmonale, a pooling of expertise in circulatory, endocrine, metabolic and renal physiology would be required. Many took up the challenge and this review will examine how much progress has since been made.

\section{Cardiac function in cor pulmonale}

This has recently been reviewed. ${ }^{3}$ Cor pulmonale was originally viewed as a form of right ventricular failure caused by hypoxia induced progressive pulmonary hypertension. Right ventricular failure can occur in severe primary and secondary pulmonary hypertension but most of the studies in patients with COPD have shown that the associated mild to moderate pulmonary hypertension does not cause significant right or left ventricular failure. Cardiac output is well maintained and oedema formation cannot therefore be explained by central pump dysfunction as occurs in classic congestive cardiac failure.

Volume status and hormonal balance

Studies in patients with both current and previous episodes of cor pulmonale show that avid salt and water retention occurs. ${ }^{4-6}$ This fact alone is not surprising and can be demonstrated in many other oedematous states including low output cardiac failure, cirrhosis, and pregnancy. An understanding of the pathogenesis of fluid retention in all these conditions has been hampered by a lack of knowledge of volume control in healthy subjects. ${ }^{7}$ A simplified scheme suggests some broad mechanisms for the development of oedema including "appropriate" fluid retention, changes in afferent signalling, altered release of hormonal mediators, and abnormal renal responses.

Fluid retention may be appropriate if there is a reduction in a critical body fluid compartment. This is the attractive idea of "effective blood volume" but it has proved difficult in practice to identify the physiological systems involved. One possibility is that the "fullness" of the arterial system is important, as determined by the balance between cardiac output and peripheral arterial vascular resistance. This type of mechanism could be a factor in cor pulmonale where the hypothetical balance may be changed by carbon dioxide induced vasodilation.

Abnormalities of afferent volume sensing receptors could also contribute to pathological oedema formation. The high pressure baroreceptors in the carotid sinus and aortic arch are one important group and increasing right arterial pressure and stretch, which release atrial natriuretic peptide (ANP), are a second group. Whilst there is no evidence that changes in afferent pathways are important in cor pulmonale, this issue has received little attention.

Circulating hormonal changes have been extensively studied in oedematous states. In low output cardiac failure baroreceptor activation of the sympathetic nervous system leads to the non-osmotic release of arginine vasopressin (AVP) and activation of the renin/angiotensin system. ${ }^{8}$ Changes also occur in cor pulmonale with raised levels of renin, aldosterone, and AVP being reported in some studies, ${ }^{3910}$ but the increases are less consistent than in classic low output failure. In addition, continuous oxygen therapy causes salt and water excretion without significant changes in hormone levels ${ }^{6}$ and these observations argue against a primary hormonal cause of the oedema. Raised levels of ANP have been reported in cor pulmonale ${ }^{11}$ but a normal physiological release of ANP occurs to salt loading. This implies that a failure to release ANP appropriately is not contributing to the fluid retention.

\section{The kidney and renal blood flow}

The kidney is the major effector system in the control of salt and water balance. Two observations have consistently been made in studies on renal function in patients with cor pulmonale: ${ }^{10}$ (1) renal blood flow (or, more correctly, effective renal plasma flow) is reduced; and (2) the glo- 
merular filtration rate remains normal in all but the critically ill patient.

Renal blood flow is reduced in stable patients with chronic respiratory failure from COPD, worsens during oedematous exacerbations, and improves again (but remains abnormal) during recovery. These changes are mirrored by alterations in the ability of patients with cor pulmonale to excrete a sodium load which is reduced during stable periods and greatly depressed during oedematous exacerbations. The study reported by Sharkey and colleagues in this issue of Thorax provides further support for the view that alterations in renal function are important in cor pulmonale. ${ }^{12}$ They used the non-invasive technique of colour flow Doppler ultrasound to assess changes in renal haemodynamics and found that the normal response of the kidney to protein loading - an increase in renal blood flow - was lost in patients with cor pulmonale. These results support and extend previous observations that the normal renal blood flow response to "renal" dose dopamine was absent in patients with advanced chronic respiratory failure from COPD. ${ }^{13}$ Both these types of renal stress test suggest that renal function (or the control of renal blood flow) is abnormal in patients with cor pulmonale.

A lack of renal reserve in cor pulmonale could explain the development of oedema. The renal vasculature is unique in having both efferent and afferent glomerular arterioles, and renal autoregulation functions to preserve glomerular filtration in times of renal stress ${ }^{14}$ when afferent (preglomerular) resistance falls and efferent (post-glomerular) resistance rises. Glomerular filtration rate is maintained, despite the fall in renal blood flow, by the increased glomerular capillary pressure upstream from the constricted efferent arteriole. However, the result of this increase in filtration fraction (glomerular filtration rate divided by renal plasma flow) is to decrease peritubular blood pressure and increase colloid osmotic pressure. Both these factors favour water and solute transfer back to the systemic circulation and would encourage the formation of oedema.

If changes in renal blood flow are fundamental to the pathogenesis of cor pulmonale, what are the mechanisms that cause these changes? Cardiac function is well maintained and reduced cardiac output cannot explain the fall in renal blood flow. Increased circulating levels of vasoconstrictor salt and water retaining hormones may occur but are probably a result of the almost universal use of diuretics rather than reflecting a causal role. It is also difficult to explain the fall in flow on the basis of abnormalities in arterial blood gas tensions. In healthy subjects moderately acute hypoxaemia increases renal blood flow and it is only with extreme hypoxaemia that falls in flow occur. ${ }^{15}$ Acute hypercapnia also increases blood flow secondary to release of catecholamines. Much less is known about the systemic vascular response to chronic exposure to hypoxaemia and hypercapnia. Alterations in vascular control occur in the pulmonary circulation and it is possible that similar systemic vascular changes occur. The response of the chronically exposed renal vasculature to further acute hypoxaemia and hypercapnia could therefore differ from that seen in the acute situation in man.
The stimulus of protein loading used by Sharkey and colleagues suggests another interesting hypothesis to explain the changes in renal haemodynamics. Protein loading creates an increased metabolic stimulus for the kidney. The lack of renal response in cor pulmonale implies that some aspect of the renal metabolic response to stress is impaired. Although cardiac output is well maintained, oxygen delivery to the kidney and other organs is reduced as a result of the transport of desaturated haemoglobin. This is clearly not sufficient to cause frank tissue anoxia (and lactic acidosis) but could limit highly metabolically active organs such as the kidney. Chronic hypercapnia could also have detrimental effects on metabolism by reducing intracellular $\mathrm{pH} .{ }^{16}$ While each of these changes alone may not alter renal function, perhaps the combination is sufficient gradually to limit and then reduce renal metabolic reserve.

The last 30 years have produced a substantial literature on cardiac, renal, and hormonal changes in patients with cor pulmonale. How much closer are we to the goal of understanding the cause of oedema in this condition? Cardiac and hormonal changes are unlikely to be causal but changes in renal blood flow are clearly important. However, the causative mechanisms remain elusive. The possibility that chronic respiratory failure alters systemic vascular control should be examined and investigations into metabolic limitations on the kidney, imposed by chronic hypoxaemia and hypercapnia, might also be rewarding.

Department of Anaesthesia and Intensive Care, S V BAUDOUIN Royal Victoria Hospital,

Newcastle upon Tyne NE1 4LP, UK

1 Campbell EJM, Short DS. The cause of oedema in "cor pulmonale". Lancet 1960;i:1184-6.

2 Medical Research Council Working Party. Long term domiciliary oxygen therapy in chronic hypoxic cor pulmonale complicating chronic bronchitis therapy in chronic hypoxic cor pulmona

3 MacNee W. Pathophysiology of cor pulmonale in chronic obstructive pulmonary disease. Parts 1 and 2. Am 7 Respir Crit Care Med 1994;150: $833-69 ; 1158-68$.

4 Farber MO, Roberts LR, Weinberger MH, Robertson GL, Fineberg NS, Manfredi $\mathrm{F}$. Abnormalities of sodium and $\mathrm{H}_{2} \mathrm{O}$ handling in chronic Manfredi F. Abnormalities of sodium and $\mathrm{H}_{2} \mathrm{O}$ handling

5 Reihman DH, Farber MO, Weinberger MH, Henry DP, Fineberg NS, Dowdeswell IRG, et al. Effect of hypoxemia on sodium and water excretion Dowdeswell IRG, et al. Effect of hypoxemia on sodium and water
in chronic obstructive lung disease. Am 7 Med 1985;78:87-94.

6 Mannix ET, Dowdeswell I, Carlone S, Palange P, Aronoff GR, Farber MO The effect of oxygen on sodium excretion in hypoxemic patients with chronic obstructive lung disease. Chest 1990;97:840-4.

7 Schrier RW. Pathogenesis of sodium and water retention in high-output and low-output cardiac failure, nephrotic syndrome, cirrhosis and pregnancy. Parts 1 and 2. N Engl f Med 1988;319:1065-72; 1127-34

8 Cannon PJ. The kidney in heart failure. N Engl ff Med 1977;296:26-32.

Farber MO, Weinberger MH, Robertson GL, Fineberg NS, Manfredi F. Hormonal abnormalities affecting sodium and water balance in acute respiratory failure due to chronic obstructive lung disease. Chest 1984;85 $49-54$

10 Richens JM, Howard P. Oedema in cor pulmonale. Clin Sci 1982;62:255-9 Stewart AG, Bardsley PA, Baudouin SV, Waterhouse JC, Thompson JS Morice $\mathrm{AH}$, et al. Changes in atrial natriuretic peptide levels during intravenous saline infusion in hypoxic cor pulmonale. Thorax 1991;46: 829-34.

12 Sharkey RA, Mulloy EMT, Kilgallen IA, O’Neill SJ. Renal functional reserve in patients with severe chronic obstructive pulmonary disease. Thorax 1997;52:411-5.

13 Howes T, Deane CR, Levine GE, Baudouin SV, Moxham J. The effects of oxygen and dopamine on renal and aortic blood flow in chronic obstructive pulmonary disease with hypoxia and hypercapnia. Am $\mathcal{F}$ Respir Crit Care Med 1995;151:378-83.

14 Hall JE. Regulation of renal hemodynamics. In: Guyton AC, Hall JE, eds. Cardiovascular physiology. IV. International review of physiology. Volume 26. Baltimore: University Park Press, 1982:243-321.

15 Hunt JM, Copland J, McDonald CF, Barter CE, Rochford PD, Pierce RJ. Cardiopulmonary response to oxygen therapy in hypoxaemic chronic airflow obstruction. Thorax 1989;44:930-6.

16 Johnson BA, Weil MH. Redefining ischemia due to circulatory failure as dual defects of oxygen deficits and of carbon dioxide excesses. Crit Care Med 1991;19:1432-7. 